\title{
Dynamic integration and network structure of the EMU sovereign bond markets
}

\author{
Ahmet Sensoy $^{1}$ - Duc Khuong Nguyen ${ }^{2} \cdot$ \\ Ahmed Rostom ${ }^{3}$. Erk Hacihasanoglu 4
}

Published online: 4 April 2018

(C) Springer Science+Business Media, LLC, part of Springer Nature 2018

\begin{abstract}
In this paper, we propose a novel concept of correlation-based stable networks to empirically investigate the dynamic integration and network structure of the European Monetary Union (EMU) sovereign bond markets. The obtained results uncover a high degree of market integration between sample markets over the period preceding the recent financial crises, while segmentation is found afterwards. The stable network analysis shows, for its part, the existence of two different network structures before and after the onset of the European debt crisis, where the in-crisis network structure is characterized by two groups of countries with respect to their fiscal performance. In particular, Belgium is the unique vertex connecting the two groups, making it the channel for shock transmission in the event of worsening debt crisis in the EMU.
\end{abstract}

Keywords Sovereign debt · European Economic and Monetary Union · Network analysis · Monetary policy $\cdot$ Tapering

JEL Classification D08 $\cdot$ E44 $\cdot \mathrm{G} 02 \cdot \mathrm{G} 12$ 


\section{Introduction}

The creation of the European Economic and Monetary Union (EMU) in January 1999 and the launch of the single currency "euro" have significantly contributed to the gradual convergence of member countries' government bonds, with the remaining yield spreads being mainly attributed to differences in the levels of idiosyncratic credit and liquidity risks (see, e.g., Abad et al. 2010; Pozzi and Wolswijk 2012). ${ }^{1}$ There is also evidence to suggest an overall increase in co-movements in the euro area bond markets (Ehrmann et al. 2011). These realities, coupled with lower unemployment and inflation rates compared to the pre-EMU levels in most participating countries (Gruner 2010), suggests that the EMU government bond markets have been interacting in a more synchronized network where flows of funds, information and expectations are transferred to each other among the member markets.

The above-mentioned financial network of EMU government bond markets with many actors and decision-makers has, however, become complex in the aftermath of the global financial crisis 2008-2009, which turned into a broader global economic recession and particularly triggered the macroeconomic and fiscal imbalances within EMU countries, after nearly 10 years of stability. During the European sovereign debt crisis, the contagious effects (both fundamentals and geographic herding contagion) are thus found to spread from the shock (crisis) country to the others with unequal intensity and magnitude (Beirne and Fratscher 2013). ${ }^{2}$ The low yields of government bonds (and spreads as compared to the yield of German government bonds) issued by the Member States of the EMU were no longer observed anymore (Sibbertsen et al. 2014). More importantly, their co-movement degree was rapidly decreasing following the occurrence of the sovereign debt crisis as shown in Fig. 1.

This structural change in the pricing of sovereign debt markets, despite a number of policy measures and initiatives undertaken by the EMU decision makers (e.g., European stability mechanism, securities market program and covered bonds purchase program), suggests that creditors have started to distinguish clearly between the different member States of the euro area. In this context, identifying the network structure of the EMU government bond markets and its time-varying features over the recent sovereign debt crisis is of paramount importance as far as multiple decision makers are concerned by the interconnection of these markets.

This paper proposes the concept of correlation-based stable networks to examine the dynamics of interconnected network of the EMU government bond markets. Our research is motivated by the fact that financial markets and institutions across countries are interconnected through a complex structure of multilateral linkages and exposures, which can be captured by a network representation of financial system (Capponin and Chen 2015).

The financial status of a particular market can change if an unexpected shock causes financial distress or large losses to its counter parties. The use of networks in describing the relationships and contagion risk between financial markets with complex interactions is a

\footnotetext{
${ }^{1}$ Abad et al. (2010) examine the sensitivity of Government bond returns to two sources of systemic risk (world and eurozone) and find that the euro markets are more sensitive to EMU risk factors than to world risk factors, an evidence that shows their increased integration over time. Pozzi and Wolswijk (2012) investigate the time-varying integration of euro area government bond markets (Belgium, France, Italy, Germany, and the Netherlands) from an ICAPM with impediments, whereby risk premiums are conditional on a countryspecific factor. They mainly document a convergence of the government bond market exposures to the common international risk factor, with no tendency to reverse during the global financial crisis 2007-2009.

2 The fundamentals contagion refers to the fact that sovereign bond markets are more sensitive to countries' economic fundamentals during the crisis period than the pre-crisis period, while the geographic herding contagion indicates that sovereign risk increased simultaneously across countries. Beirne and Fratscher (2013) find evidence of the geographic herding contagion for the euro area countries in 2008 and between August and September 2011.
} 
new research strand and helps, from an operational point of view, design market and regulation policies (see, e.g., Pragidis et al. 2015; Barro and Basso 2010; Markellos et al. 2016). The proposed approach, which combines the dynamic network theory with the consistent Dynamic Conditional Correlation FIAPARCH model (cDCC-FIAPARCH), is particularly advantageous in that it allows one to not only gauge the financial integration and segmentation structure of the EMU government bond markets before and after the sovereign debt crisis, but also to detect the underlying mechanisms of shock transmission. All in all, the obtained results would help investors and policy makers to anticipate the potential paths for crisis/recovery transmission in the future. Our study thus contributes to the recent research strand which tackles the contagion and systematic risk issues during the European debt crisis (see, e.g., Pragidis et al. 2015; Paltalidis et al. 2015; Reboredo and Ugolini 2015; Dewachter et al. 2015).

Using daily data of 10-year benchmark government bond yields for eleven EMU countries over the period 2002-2014, our results indicate that investors have clearly distinguished between the different EMU members during the European debt crisis. More precisely, there is a decreasing tendency of overall correlation among the sample markets since 2013, which can be attributed to the existence of different network clusters. In particular, the co-movement is high among bond markets of the same cluster, but low between clusters. In this new normal environment, the EMU sovereign bond markets are clearly divided into two groups with similar performance of fiscal policy, where Belgian debt market is the common vertex and can thus have a critical role in monitoring the future stability and recovering of the EMU debt markets. The results are robust to alternative stability and correlation strength parameter selections when constructing the stable networks. Our findings also put forward the role of the Federal Reserve tapering moves and liquidity decreases in explaining the recent developments in the EMU debt markets (i.e., they tend to co-move in greater harmony) rather than their economic fundamentals.

The rest of the paper is organized as follows. Section 2 presents the data and the methodology we use to conduct the empirical investigation. Section 3 reports the results. Section 4 concludes the paper.

\section{Data and methodology}

We consider daily 10-year benchmark government bond yields for a sample of eleven countries to carry out our empirical analysis. These countries include Austria, Belgium, Finland, France, Germany, Greece, Italy, Ireland, Netherlands, Portugal, and Spain. The data are obtained from Thomson Reuters Datastream. The sample spans a time period from March 1, 2002 (end of dual circulation period in Greece) until May 2, 2014, which specifically captures the various phases of financial linkages in the European sovereign bond markets over the last 12 years.

Figure 1 displays the patterns of changes in sovereign bond yields over the study period. We observe a convergence of bond yields in the EMU during the first 10 years. Then, the 10 -year bond yield of Greece has increased sharply, which marked the beginning of the European debt crisis and the divergence phase. The bond yields of Ireland, Italy, Portugal and Spain also increased, while those of other countries such as Finland, France, and Germany decreased. This phenomenon seems to reflect the investors' distinction between sovereign debt markets with respect to their credit quality. Finally, there is, since 2013, a tendency towards an harmony of bond yields. 


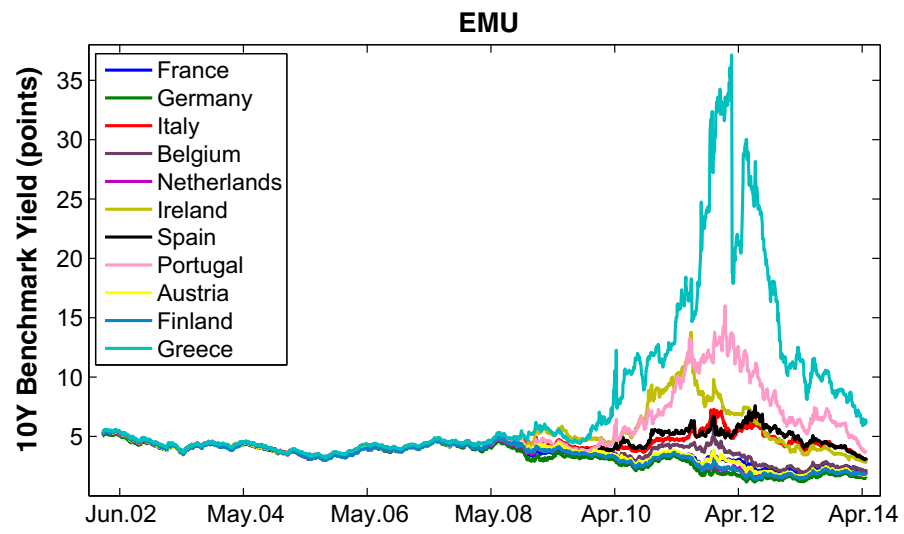

Fig. 1 EMU sovereign bond yields from March 2002 to May 2014

In what follows, we apply the consistent Dynamic Conditional Correlation FIAPARCH (cDCC-FIAPARCH) of Aielli (2013) to track the degree of time-varying co-movement between these markets. This model also helps identify shifts in the co-movement structure and the exact timing of bond yield co-movements.

\subsection{Consistent dynamic conditional correlation}

The dynamic conditional correlations are estimated by the cDCC process as in Aielli (2013). To do so, we first compute the daily changes in sovereign bond yields (BY) by taking the first differences for each sample country $i$ as follows:

$$
r_{i, t}=\triangle B Y_{i, t}=B Y_{i, t}-B Y_{i, t-1}
$$

We take out the days when more than half of the markets are closed to ensure the accuracy of model estimations. Moreover, the highest and lowest five daily changes of each market are removed from the dataset to get rid of outliers. To remove the serial correlation effects (which are present in all daily changes) and obtain the zero-mean residuals for further statistical analysis, we estimate the following mean equation:

$$
r_{t}=\mu+\phi r_{t-1}+\epsilon_{t}
$$

where $r_{t}=\left[r_{1, t}, \ldots, r_{n, t}\right]^{\prime}$ is the vector of $n$ bond yield daily changes; $\mu$ is a vector of constants with length $n ; \phi$ is the coefficient vector corresponding to autoregressive terms; and $\epsilon_{t}=\left[\epsilon_{1, t}, \ldots, \epsilon_{n, t}\right]^{\prime}$ is the vector of residuals.

In the next step, we obtain the conditional volatilities $h_{i, t}$ from the univariate FIAPARCH $(1, d, 1)$ model for an extended flexibility, as it allows to explicitly accommodate asymmetric effects and long memory in volatility processes. The FIAPARCH $(1, d, 1)$ model is given by

$$
h_{i, t}^{\delta / 2}=\omega+\left\{1-[1-\beta L]^{-1}(1-\phi L)(1-L)^{d}\right\}\left(\left|\varepsilon_{i, t}\right|-\gamma \varepsilon_{i, t}\right)^{\delta}
$$

where $\omega \in(0, \infty),|\beta|$ and $|\phi|<1,0 \leq d \leq 1, \gamma$ is the leverage (asymmetry) coefficient which captures the volatility reaction to negative and positive shocks, and $\delta$ is the parameter for the power term that takes finite positive values. $(1-L)^{d}$ is the financial differencing 
operator expressed in terms of a hyper-geometric function [see Conrad et al. (2008) for the expression of this function]..$^{3}$

Once the mean and variance equations are specified, the DCC process proposed by Engle (2002) can be modelled based on transformed residuals.

Let's assume that $E_{t-1}\left[\epsilon_{t}\right]=0$ and $E_{t-1}\left[\epsilon_{t} \epsilon_{t}^{\prime}\right]=H_{t}$, where $E_{t-1}[\cdot]$ is the conditional expectation up to time $t-1$. The conditional covariance matrix $H_{t}$ can be written as

$$
H_{t}=D_{t}^{1 / 2} R_{t} D_{t}^{1 / 2}
$$

where $R_{t}=\left[\rho_{i j, t}\right]$ is the conditional correlation matrix and the diagonal matrix of the conditional variances is given by $D_{t}=\operatorname{diag}\left(h_{1, t}, \ldots, h_{n, t}\right)$. Engle (2002) models the right hand side of Eq. (3) rather than $H_{t}$ directly and proposes the following dynamic correlation structure:

$$
\begin{aligned}
R_{t} & =\left\{Q_{t}^{*}\right\}^{-1 / 2} Q_{t}\left\{Q_{t}^{*}\right\}^{-1 / 2}, \\
Q_{t} & =(1-a-b) S+a u_{t-1} u_{t-1}^{\prime}+b Q_{t-1},
\end{aligned}
$$

where $Q_{t} \equiv\left[q_{i j, t}\right], u_{t}=\left[u_{1, t}, \ldots, u_{n, t}\right]^{\prime}$ and $u_{i, t}$ is the transformed residuals, i.e., $u_{i, t}=$ $\epsilon_{i, t} / h_{i, t}, S \equiv\left[s_{i j}\right]=E\left[u_{t} u_{t}^{\prime}\right]$ is the $n \times n$ unconditional covariance matrix of $u_{t}, Q_{t}^{*}=$ $\operatorname{diag}\left\{Q_{t}\right\}$ and $a, b$ are non-negative scalars satisfying $a+b<1$. This modelling is called DCC.

However, Aielli (2013) shows that the estimation of $Q$ by this way is inconsistent since $E\left[R_{t}\right] \neq E\left[Q_{t}\right]$ and thus proposes the following consistent model with the correlation driving process

$$
Q_{t}=(1-a-b) S+a\left\{Q_{t-1}^{* 1 / 2} u_{t-1} u_{t-1}^{\prime} Q_{t-1}^{* 1 / 2}\right\}+b Q_{t-1}
$$

where $S$ is the unconditional covariance matrix of $Q_{t}^{* 1 / 2} u_{t}$.

Finally, we compute the average cDCC to consider the time-varying correlation of the EMU bond yields at the group level, such as

$$
\bar{\rho}_{t}=\frac{2}{n(n-1)} \sum_{i=1}^{n-1} \sum_{j=i+1}^{n} \rho_{i j, t}
$$

\subsection{Correlation-based stable networks}

Our integrated framework can be divided into two main parts. The first one consists of obtaining the dynamic conditional correlation matrix $R_{t}$, and the second one is the modeling of the financial networks based on time-varying correlations of sovereign bond yields we obtain in Sect. 2.1. It is worth noting that networks have recently become an important tool in financial economics and proven to be an efficient way to characterize and investigate a wide range of complex financial systems including stock, bond, commodity, foreign exchange, and

\footnotetext{
3 In financial time series, one of the most common stylized facts is the volatility clustering which can be captured by GARCH process. However, GARCH process can not capture the asymmetric effects of the positive and negative shocks on volatility. In addition to that, conditional variance need not be a linear function process of lagged square residuals or lagged absolute residuals which leads us to the Asymmetric Power ARCH models. Finally, we would like to capture the long range dependence on conditional volatility which is a common phenomenon in financial time series, leading us to the fractionally integrated volatility models. To obtain the richest volatility dynamics, we use the FIAPARCH modeling proposed by Tse (1998).
} 
interbank lending markets. ${ }^{4}$ Moreover, from an operational research point of view, they have been started to use in financial decision making processes as in the work of Nagurney and $\mathrm{Ke}$ (2006) where authors develop a framework to analyze the financial network equilibrium problems with intermediation and variable weights, and as in the work of Barro and Basso (2010) where the credit risk of a portfolio of bank loans is investigated within a dynamic framework. In this scheme of things, a correlation-based network would be very useful in understanding the financial integration and segmentation structure of the EMU bond markets in our case. Such an approach has not been used in the relevant literature before and we expect it to provide noteworthy financial and policy implications regarding the subject. To be able to follow our approach, we first need to give some introductory context.

Suppose that an undirected and unweighted network $N_{t}$ evolves in time and includes at most $k$ nodes from the set $\left\{n_{1}, n_{2}, \ldots, n_{k}\right\}$ on any given time step $t$. At that time $t$, let some (or all) of the nodes in the network be connected to each other according to some $t$-dependent criterion. As can be easily understood, in this construction, the nodes included in the network and the edges connecting these nodes need not to be stable and are subject to change in time. Now, we introduce the following genuine definitions.

Definition 1 Let $N_{t}$ be a dynamic network described as above. Let $e_{i j}$ be an edge connecting specific nodes $n_{i}$ and $n_{j}$, and the time variable $t$ spans the set $\left\{t_{1}, t_{2}, \ldots, t_{m}\right\}$. Suppose $e_{i j}$ appears in the network $s$ out of $m$ times. Then if $1 \geq \frac{s}{m} \geq p>0, e_{i j}$ is called a p-stable edge or $p$-stable connection..$^{5}$ A network $M$ consisting of only $p$-stable connections of $N_{t}$ is called p-stable network of $N_{t}$.

Definition 2 Let $R_{t}$ be the cDCC matrix defined in Sect. 2.1. At time $t$, let $\bar{\rho}(t)$ be the mean of the lower triangular part of $R_{t}$, and $\sigma(t)$ be its standard deviation. A correlation level $\rho_{i j}(t) \in R_{t}$ is called $c$-strong if $\rho_{i j}(t) \geq \bar{\rho}(t)+c \cdot \sigma(t)$ where the constant $c \geq 0 .{ }^{6,7}$

Then, our approach can be described as follows. For a pre-determined strength level $c$, we construct a dynamic network $N_{t}$ consisting of nodes connected by only $c$-strong correlations at time $t$, where nodes represent the sample countries. Next, for the considered time period, we construct $M$; the $p$-stable network of $N_{t}$. For relatively high $p$ values, we can intuitively state that members connected in $M$ are integrated. As $c$-level is chosen higher, this integration degree gets stronger.

In the following section, we will study the integration/segmentation structure of the EMU bond markets by analyzing the $p$-stable connections. For the sake of simplicity in our setup, we introduce the following definition which will be our main focus throughout the rest of this study.

Definition 3 A network $M$ is called simply-stable, if it only consists of $p$-stable connections of $N_{t}$ obtained from $c$-strong correlations where $c=0$ and $p=0.5$.

\footnotetext{
4 For example, see Iori et al. (2008), Tola et al. (2008), Tumminello et al. (2010), Minoiu and Reyes (2013), Caccioli et al. (2015) for some of the noteworthy studies in recent years.

5 It is clear that every $p_{1}$-stable connection is also $p_{2}$-stable for any $p_{2} \leq p_{1} \leq 1$.

6 It would be naive to choose a fixed threshold level to determine if a correlation value is strong or not. Several studies in the literature have shown that correlations are time-varying and tend to increase in turbulent times. Therefore, a fixed choice would most likely introduce a bias depending on the global conditions. With our model, the threshold level is determined endogenously and updated everyday. Thus, possible bias arising due to changing global conditions is minimized.

7 When $c<0, c$-strong correlation levels become below the average. In order to consider a reasonable strength concept for correlations, minimum $c$ should be taken as 0 .
} 
This last definition associates the concept of stability with the observation of an average event at least half of the time which is, indeed, intuitive. From a methodological point of view, the third definition can later be diversified as super-stable by imposing stronger connectivity and stability conditions.

\section{Dynamic linkages of the EMU debt markets}

Figure 2 displays the average dynamic correlation between the bond yields of the EMU countries, which is computed from the cDCC-FIAPARCH model. Accordingly, we observe that the early years of the EMU exhibit an almost perfect bond market integration with an average correlation estimate above 0.8 . This high level of integration reflects a gain in importance of aggregated European factors over local country-specific ones. The dynamics of bond market linkage in the EMU then had abrupt changes, with respect to two critical dates. The first one was the 15th of September 2008 which marked the collapse of Lehman Brothers Holdings Inc. While this event did not have an important impact on the EMU government bond yields relative to the German Bund (see, Fig. 1), Fig. 2 clearly shows that it seems to cause the start of divergence process among the EMU sovereign bond markets given the sharp decrease in the correlation of bond yields.

The second date is the 5th of November 2009, the date when the Greek government revealed a revised budget deficit of $12.7 \%$ of GDP for 2009, which was double the previous estimate. This time, not only the average correlation falls down dramatically from a high level of 0.8 to the lowest level of about 0.2 in April 2012, but also the sovereign bond yields and spreads relative to the German Bund rise sharply for most of the EMU countries. ${ }^{8}$ Country-specific factors related to economic fundamentals and sovereign debt quality have been identified as the most relevant sources of this divergence. A new concordance period of bond yields is subsequently observed from May 2014 without obvious reverses.

Our findings based on the cDCC are thus broadly consistent with those of Pozzi and Wolswijk (2012) who developed an analytical framework that allows the gradual shifts of selected EMU sovereign bond markets (Belgium, France, Germany, Italy, and the Netherlands) from a full ICAPM with investment barriers to a standard ICAPM. Indeed, their dynamic integration analysis over the period 1995-2009 shows evidence of a convergence process where country-specific factors are almost removed by 2006 with an exception of Italy, but these factors reappeared during the 2007 Sub-prime crisis and the subsequent global financial crisis 2008-2009. More importantly, the exposure of the EMU government bond markets to common international risk factors converges over time and is not affected by the recent crises. Christiansen (2014) uses the R-square approach to examine the integration of the EU government bond markets (i.e., the explanatory power of the OLS regression of common risk factors on the bond returns) and documents that markets with low credit ratings are less integrated with the others and that the level of integration between EMU markets is lower during periods of the recent crises (both the global financial crisis and the European debt crisis). To a larger extent, Reboredo and Ugolini (2015) show from a copula-CoVaR approach that the EMU sovereign bond markets behave similarly in terms of systematic risk before the advent of the European debt crisis, and that they have become more decoupled afterwards, even though systemic risk increased for non-crisis countries.

8 Estimated model parameters can be found in Appendix A. 


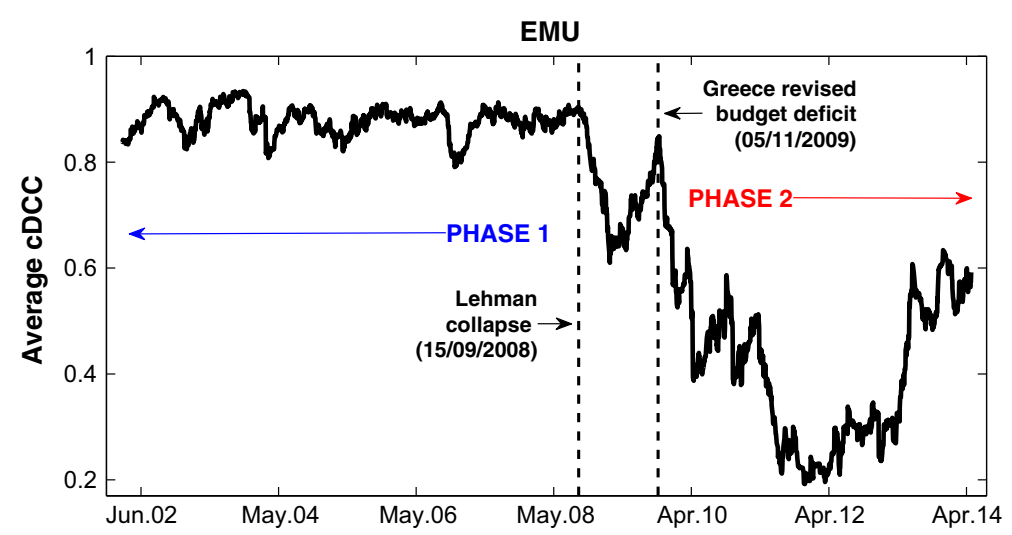

Fig. 2 Average dynamic conditional correlation between EMU sovereign bond yields. Vertical lines denote two specific critical dates for the region

\subsection{Network analysis}

We now consider the effects of the European sovereign debt crisis on the integration/segmentation structure of the EMU bond markets. For this purpose, we exclude the time period marked by the Sub-prime crisis and the global financial crisis, and focus particularly on the dynamics of bond yields during Phase 1 and Phase 2, as indicated in Fig. 2: Phase 1 is taken as the time interval between 1 March 2002 and 14 September 2008 (6.5 years), whereas Phase 2 covers the period from 6 November 2009 to 2 May 2014 (4.6 years).

We show, in Fig. 3, the stable networks during Phase 1 and Phase 2, which are constructed using the methodology presented in Sect. 2.2. ${ }^{9}$ In Table 1, we present the major centrality scores of the sample EMU members belonging to simply-stable networks in Phase 1 and Phase 2. In network theory, the centrality of a node determines the relative importance of that node within a network. We use node degree, betweenness centrality, and closeness centrality as our main importance measures. These measures are defined as follows.

Node degree is the number of nodes that is adjacent to it in a network.

Betweenness centrality measures the importance of a node as an intermediate part between other nodes. For a given node $k$, it is defined as

$$
B(k)=\sum_{i, j} \frac{n_{i j}(k)}{m_{i j}}
$$

where $n_{i j}(k)$ is the number of shortest geodesic paths between nodes $i$ and $j$ passing through $k$, and $m_{i j}$ is the total number of shortest geodesic paths between $i$ and $j$.

Closeness centrality is a measure of the average geodesic distance from one node to all others. This measure is high for strongly connected central nodes and low for poorly connected ones. For node $i$ in a network with $N$ nodes, it is defined as

$$
C(i)=\frac{1}{\sum_{j=1}^{N} d(i, j)}
$$

where $d(i, j)$ is the minimum geodesic path distance between nodes $i$ and $j$.

9 The size of the circles in the figures do not have any economic interpretation and are chosen for optimal allocation purposes when constructing networks. 


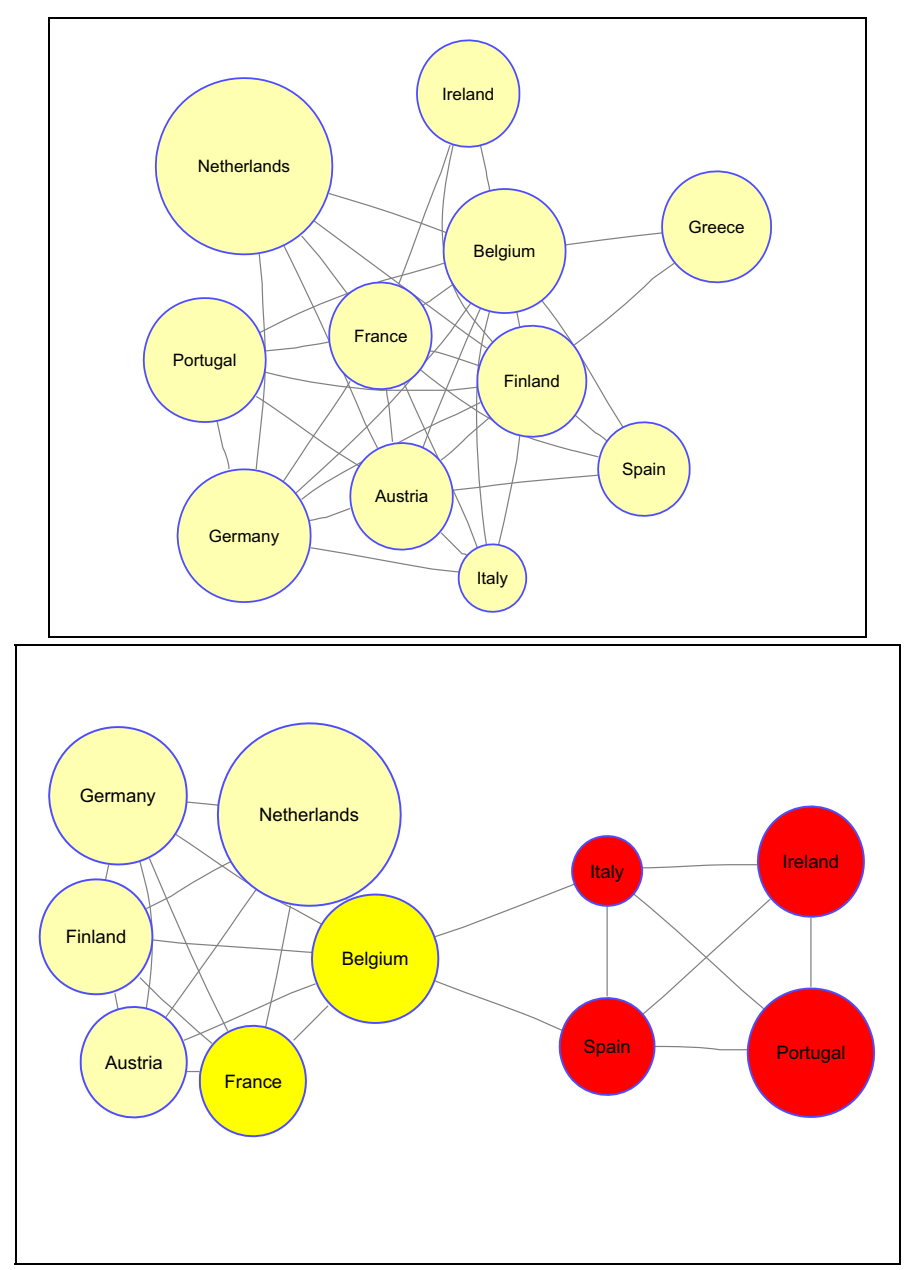

Fig. 3 Simply-stable networks in Phase 1 (upper sub-figure) and Phase 2 (lower sub-figure)

For all these centrality measures, the larger they are, the more important the node is. Therefore, we basically see two different networks with asymmetric links between sample sovereign bond markets. In Phase 1, a high degree of integration among sample markets is observed as almost every sovereign debt market in the EMU is connected to at least two other markets. This is officially validated by the average node degree per node in Phase 1 (6.2) which is significantly greater than the average node degree in Phase 2 (4.2). As expected, Austria, Belgium, Finland, France and Germany are located at the center of the network structure and have multiple edges (complex structure of relationships), thus indicating not only their high degree of integration with the other markets but also their high connectedness with them. This is also reflected on the betweenness degrees of each of these members in Phase 1 given in Table 1, since these are the only members that have betweenness scores greater than zero. The results of integration analysis in Christiansen (2014) also provide evidence of high integration degrees for these countries, while explaining this feature by their high credit quality. 
Table 1 Centrality scores of the simply-stable networks in Phase 1 and Phase 2

\begin{tabular}{|c|c|c|c|c|c|c|}
\hline & \multicolumn{2}{|l|}{ Degree } & \multicolumn{2}{|c|}{ Betweenness } & \multicolumn{2}{|c|}{ Closeness } \\
\hline & Phase1 & Phase2 & Phase 1 & Phase 2 & Phase 1 & Phase 2 \\
\hline France & 9 & 5 & 3.6 & 0 & 0.091 & 0.054 \\
\hline Germany & 7 & 5 & 0.6 & 0 & 0.077 & 0.054 \\
\hline Italy & 5 & 4 & 0 & 6 & 0.067 & 0.058 \\
\hline Belgium & 10 & 7 & 7.6 & 20 & 0.100 & 0.074 \\
\hline Netherlands & 5 & 5 & 0 & 0 & 0.067 & 0.054 \\
\hline Ireland & 3 & 3 & 0 & 0 & 0.059 & 0.041 \\
\hline Spain & 4 & 4 & 0 & 6 & 0.063 & 0.058 \\
\hline Portugal & 5 & 3 & 0 & 0 & 0.067 & 0.041 \\
\hline Austria & 8 & 5 & 1.6 & 0 & 0.083 & 0.054 \\
\hline Finland & 10 & 5 & 7.6 & 0 & 0.100 & 0.054 \\
\hline Greece & 2 & 0 & 0 & 0 & 0.056 & 0.000 \\
\hline
\end{tabular}

On the other hand, Phase 2 is clearly characterized by a segmentation structure. This segmentation is obvious not only in view of the significant decreases in the average node degree in Phase 2, but also observed through the significant decreases in closeness and betweenness centralities in the same period. There are two main clusters where the member countries struggling with public debt problems (denoted in red) together form one cluster. Indeed, the average debt-to-GDP ratios as provided by Eurostat for these countries over the period 2010-2014 range from $81.6 \%$ (Spain) to $123.2 \%$ (Italy). ${ }^{10}$ In the other cluster, we observe the countries with stronger fiscal positions during the sovereign debt crisis period (Austria, Belgium, Finland, France, Germany, and Netherlands).

It is worth noting that, with a 2010-2014 average debt-to-GDP ratio of 166.64\%, Greece is not connected to any other member country in Phase 2, which reveals that its debt market no longer belongs to the same asset class with the others and currently stands as an outlier in the EMU. Another important fact is that the decrease in the overall correlation level in Phase 2, as shown by simply-stable networks, is not due to a general divergence of EMU members. Instead, it is more likely to be caused by clusters of countries that exhibit high within-cluster co-movement but not between-cluster co-movement.

Figure 3 highlights an intermediate role of Belgium as a connection hub in the new segmented structure because the two main clusters are connected through this country during Phase 2. This change in the network structure is also confirmed by the statistics in Table 1 where Belgium has the highest betweenness centrality score of 20, which is almost three times the value in Phase 1, as well as the highest closeness score of 0.074. In other words, the Belgian sovereign debt market has become a greater transmitter of shocks between the two clusters during the sovereign debt crisis period, and could play a crucial role in monitoring the systemic risk in the EMU. Belgium's role is very likely related to the evolution of its fiscal performance relative to other countries in the sample. According to Eurostat, the average government surplus/deficit as percentage of GDP ranges from $-7.37 \%$ (Greece) to $3.50 \%$ (Finland) over the period 2002-2008 (Phase 1). ${ }^{11}$ With a ratio of $-0.80 \%$, Belgium is

\footnotetext{
${ }^{10}$ Debt is measured as the consolidated general government gross debt at nominal (face) value, outstanding at the end of the year. This debt-to-GDP ratio is defined in the Maastricht Treaty.

11 Detailed statistics are provided upon requests.
} 
among the top performers in terms of fiscal position. In the 2010-2014 period (Phase 2), all sample countries experienced fiscal deficit (averaged from $-1.37 \%$ in Germany to $-12.72 \%$ in Ireland), and Belgium maintained an upright level from the previous period $(-3.98 \%)$, which effectively separates the two clusters we identified in Fig. 3. Note that Belgium has a lower deficit level than France $(-5.32 \%)$ during the same period, but weaker fundamentals due to its high public debt level (103.54\% versus $88.88 \%$ ) coupling with near-zero growth, high labor cost, and very low inflation. The failure of Flemings and Walloons to form a government in the late 2010 also triggered the anxieties from policymakers and investor community.

The position of Belgium during Phase 2 has two main implications. On the one hand, Belgium could be the next "sick man" of the Eurozone in the event that the sovereign debt crisis worsens. In this case, harmful crisis spillover effect will take place through this country first, before it contaminates other countries. Our finding thus corroborated the rising concerns about Belgium's debt-trap fears as of December 2010 and the downgrade alert of its creditworthiness by Fitch Ratings in November 2014, which typically signaled the possible move of the European debt crisis to the core of the EMU. On the other hand, if a recovery is to be observed, it will most likely happen by the convergence of bond yields of struggling (in-crisis) member countries to the yields of Belgium.

To examine the robustness of our main results, we also display the stable-networks in Phase 1 and Phase 2 for alternative stability $(p)$ and correlation strength $(c)$ parameter selections. In our main analysis, we use $p=0.5$ and $c=0$, whereas the following figures show how these stable networks may change when we strengthen the conditions to construct them. In Fig. 4, we increase the $c$-level, therefore it becomes much harder to state that a correlation is strong. In this new structure, we see that stable networks in Phase 1 still tend to include all members and have a dense structure whereas in Phase 2, links between nodes get broken further and we see even more segmentation in the market.

Very similar results also arise in the case of increasing the $p$-level, i.e., the stability the condition. In this case, we significantly need more appearance of some node $n_{i j}$ in the dynamic network structure in order to call it a stable one. We see, in Fig. 4, that even though we strengthen the stability condition, stable networks in Phase 1 tend to become a single cluster with a dense structure. On the other hand, the connectedness breaks further in Phase 2, yielding to a more segmented structure (Fig. 5).

\subsection{Path to recovery?}

In addition to the two critical dates provided in the previous section, we now look at two other dates which featured the recent development of the EMU sovereign debt markets since 2010 where those of Greece, Ireland, Italy, Portugal and Spain had been successively under intense pressure. The first additional critical date is the 7th of April 2011, the date when Portugal requested immediate assistance from the European Financial Stability Facility (EFSF) and also the date when the European Central Bank (ECB) increased interest rates by 25 basis points, which is a very controversial decision considering the euro area's status at that time. After this event, the spreads between the EMU sovereign bonds even expanded and the average correlation hit bottom, hovering around the 0.2 level.

Later, the ECB took policy decisions such as lowering interest rates to stimulate economic activities and local policy makers promised structural reforms in these countries. Although these reactions seem to have been effective on spreads (see Fig. 1), Fig. 6 reveals that they are not enough to force the EMU bond yields to act as a single asset class as in the period preceding the bankruptcy of Lehman Brothers. 


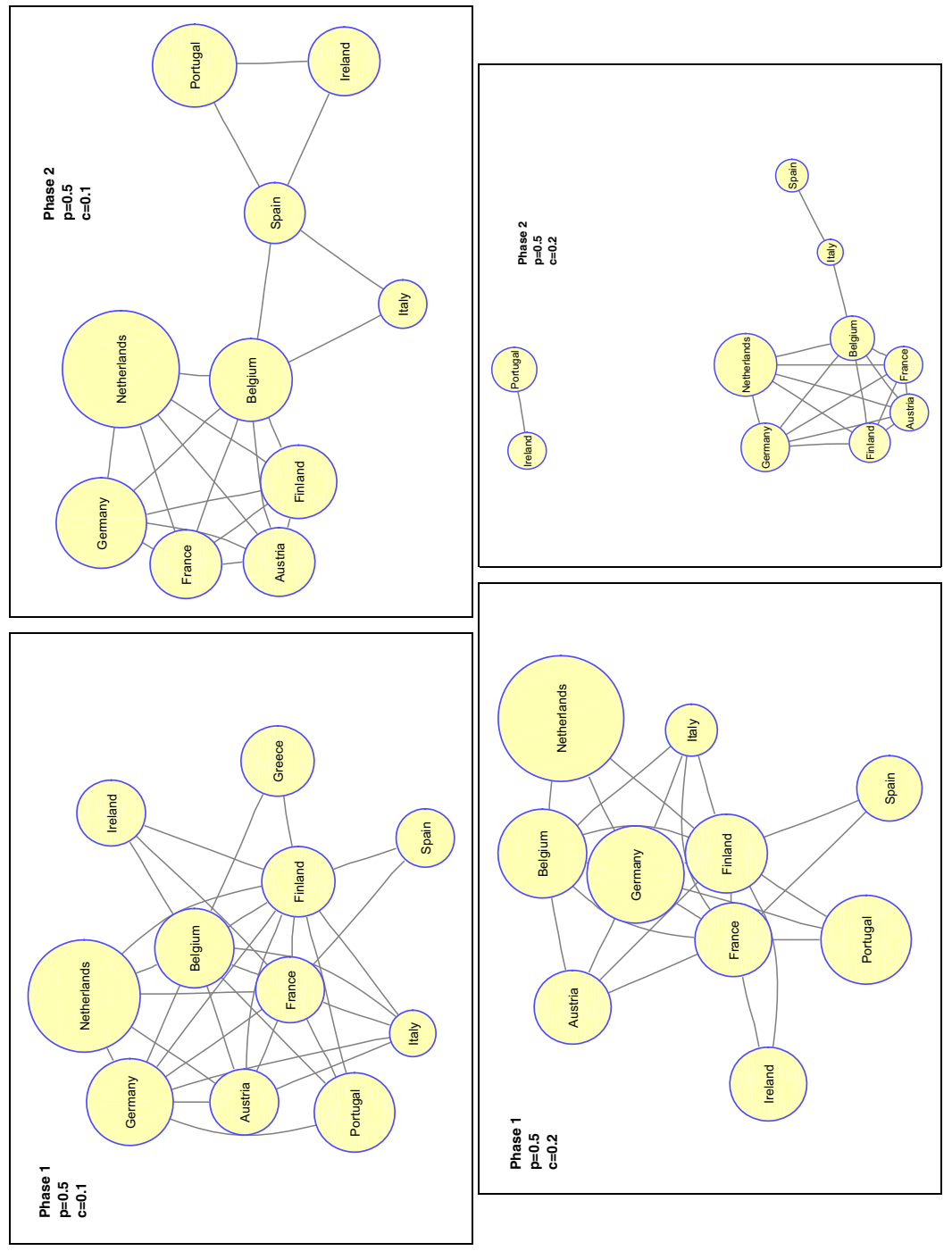

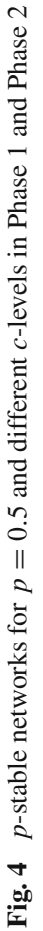




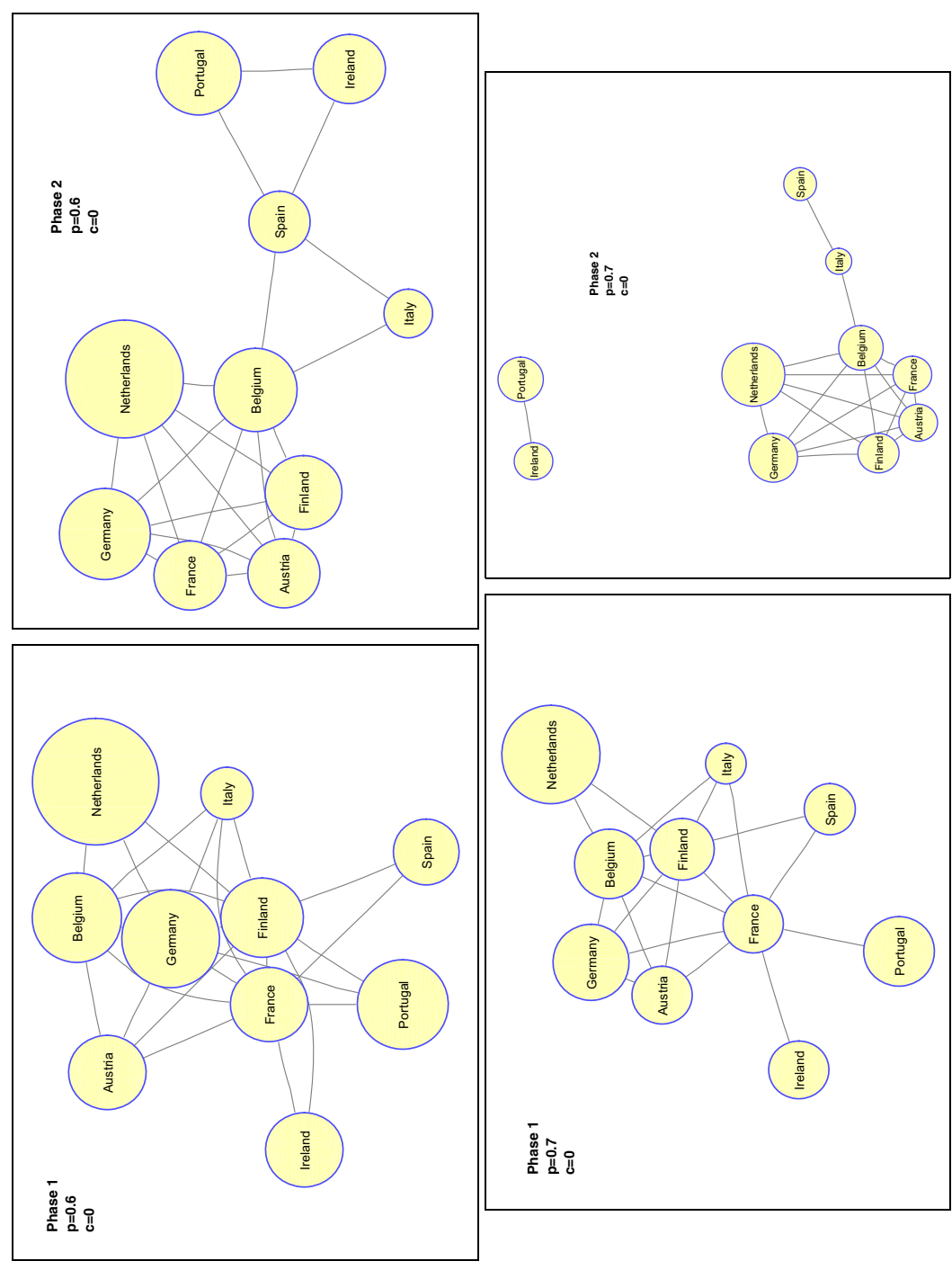

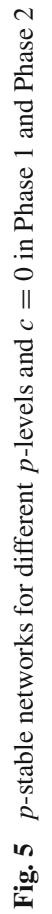



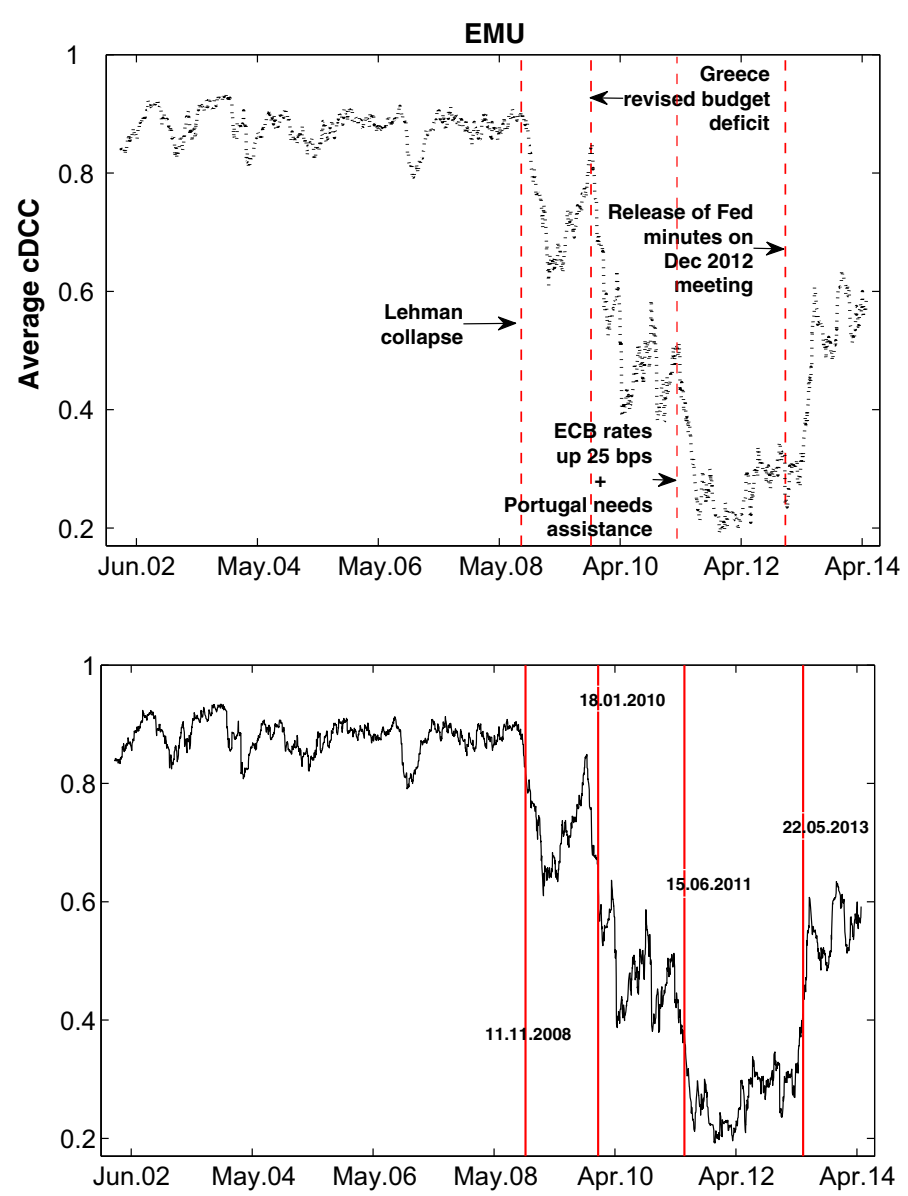

Fig. 6 Average dynamic conditional correlation between EMU sovereign bond yields. Vertical lines in the upper sub-figure denote the dates when noteworthy economic incidents occur. Vertical lines in the lower subfigure denote the dates when dynamic correlation shifts to another mean level according to penalized contrasts

From the beginning of 2013, we observe a significant increase in the EMU bond market co-movements with a decreasing trend in their yields (see Figs. 1,6). Although we cannot say it formally, this situation seems to draw a picture of going back to the pre-Lehman Brothers network structure. An interesting question then arises as to what could be the drivers of these changes. Recent studies show that in the eurozone, fiscal rules, debt, deficits, and debt-service ratios play the main roles in determining the sovereign spreads (Schuknecht et al. 2009; Fatas 2010; von Hagen et al. 2011; Bernoth et al. 2012; Iara and Wolff 2014). Therefore, if aforementioned significant changes in the sovereign bond yield trends and correlation dynamics are to be observed from 2013, we would then expect at least a recovery or signs of recovery in terms of fiscal performance of the EMU members prior to 2013. However, this is not the case here. One possible explanation seems to be related to the second additional critical date, the 3rd of January 2013, when the minutes of the US Fed's FOMC meeting on 12-13 December 2012 were released. The importance of the meeting was that for the first 
time, there was some uncertainty on how long the Fed should keep buying bonds. ${ }^{12}$ Indeed, the so called "Fed tapering" operation that was formally announced by Bernanke on May 22, 2013, seems to be uttered in this meeting.

While it is not proved in this study, it is likely that the public announcement of the Fed tapering possibility has important influence on the changes we observe in the EMU bond markets, and this impact is transmitted through the "flight-to-quality" mechanism. Indeed, when the differences in government bond yields have sharply increased in the euro area for the first time, the main explanation was that the market players have been shaken through a wake-up call triggered by the global financial crisis and started to distinguish between the different EMU member countries (Beber et al. 2009).

However, in the case of first Fed tapering rumours in early 2013 and the following vanishing excess liquidity environment, the flight-to-quality mechanism again is in place, but this time, the flight comes from emerging markets to developed markets worldwide as quality haven. ${ }^{13}$ The problem is that in the previous case, low and high quality addresses were mainly based on solid fiscal performances (Schuknecht et al. 2009; von Hagen et al. 2011; Bernoth et al. 2012; Iara and Wolff 2014). However in the current case, emerging countries, where the flight takes off, are better off in terms of these fiscal performances in general, compared to the target addresses i.e., EMU members including the problematic ones. ${ }^{14}$

Overall, the situation after Fed tapering rumors suggests that during the recent recovery period in EMU, not the quality but the "illusion of quality" (probably due to fiscal history of developed and emerging countries) takes a big role. Of course, one could argue that the main influence was originated from the heightened confidence in distressed governments' commitment towards sustainable fiscal policies, ${ }^{15}$ and the forthcoming macro-prudential regulations of ECB. However, it should be kept in mind that commitments from governments and policy responses from ECB took place occasionally during 2009-2012 and both did not seem to be enough for a healthy recovery and did not force these yields to act as a single asset class back then. ${ }^{16}$

Finally, by using the penalized contrast function methodology of Lavielle (2005), we formally present the dates when the average correlation shifts to different mean levels in Fig. $6 .{ }^{17}$ We can see that within short time intervals, the aforementioned critical events triggered structural changes in the correlation dynamics. Since May 2013, the EMU members seem to benefit from the illusion of quality as the upward pressure on their bond yields' spreads have loosened and the coherency in the bond yield movements has been improving significantly. Therefore, struggling members have time to implement structural reforms until

\footnotetext{
12 http://news.yahoo.com/fed-minutes-show-concerns-bond-190130672.html.

13 We observe severe capital outflows from emerging markets during this period. Due to these outflows, currencies of Chile, India, Brazil, Turkey, South Africa and Indonesia experienced depreciations ranging between 10 and $26 \%$ in 2013. Similarly, several emerging sovereign bond yields shot up and equity markets in some of these countries loss up to $30 \%$ of their values.

14 For example, developed countries worldwide were averaging about $100 \%$ debt to GDP ratio while in the emerging countries this ratio was averaging around only about $40 \%$ by the end of 2012 . Similar considerable differences in other fiscal indicators were also observed.

15 For example, see Codogno et al. (2003), Barrios et al. (2009) for earlier studies on the subject.

16 Although it is not the scope of this paper, further research could seek answer to the rhetorical question of "do we need any other central banks then Fed?". Naturally, the answer would be "yes" but the idea is to stress on the challenges faced with other central banks when one clearly dominates the others.

17 The main advantage of this methodology is that it does not impose any condition on the dependency and distribution of the data. For details, see Lavielle (2005).
} 
the next excess liquidity environment for whatever the reason. Moreover, a shift in expectations due to this illusion can lead to a further self-fulfilling wave of cross-border capital flows, which would definitely support EMU members on this path. ${ }^{18}$

\section{Conclusion}

This paper develops a correlation-based stable network approach to examine the recent developments observed in the EMU sovereign bond markets. This approach, which combines the cDCC-FIAPARCH and the simply-stable network structure, allows us to gauge the stability of identified networks over time, to the extent that the connectivity within the sample EMU bond markets might be time-varying. We first model and investigate the dynamic linkages (integration/segmentation) of sample markets both before and after the onset of the European debt crisis that triggered eurozone countries since the end of 2009, and then construct their dynamic networks based on the conditional correlations estimated in the first stage.

Our results show an almost perfect integration of the EMU sovereign bond markets in the pre-crisis period. The integration structure is then severely damaged, reflected by an all time low group correlation in the EMU, following the collapse of Lehman Brothers and the release of fiscal problems in Greece. On the other hand, the simply-stable network analysis uncovers two different network structures before and after the occurrence of the European debt crisis, with a decreasing trend of the overall correlation over the in-crisis period. This decrease in the cross-market co-movement is found to be not related to a general dispersion of the EMU member countries, but rather caused by clusters of countries that exhibit high within-cluster co-movement but not between-cluster co-movement. Accordingly, in its new network structure, the EMU sovereign bond markets are segmented into two main groups where fiscal performance seems to be the main reason for this segmentation. Moreover, these two main parts are connected through only one member, Belgium. This situation suggests that the path to recovery in a positive outlook or the transmission of crisis shock in the opposite case will take place through this member and its debt market should be carefully monitored by policy makers and investors.

A discussion of result implications on the recovery signals and, in particular, the recent increased harmony in the EMU sovereign bond markets was also conducted. It appears that that the EMU fundamental indicators did not play an effective role in this case, as they were in a much worse situation compared to pre-crisis levels and did not even show promising performance until the start of the convergence process in early 2013. Alternatively, transitions were mainly attributed to the Fed tapering rumors originated in early 2013 and the following diminishing excess liquidity environment. This chain of events eventually created an instinct of "need to flight-to-quality" from emerging countries to developed ones, even though fiscal performances tell that a different story should have been written. The results naturally bring out the following question: If the turmoil observed during 2008-2009 was a self-correction in financial markets then, were EMU bond markets overvalued pre-2008 or are they undervalued post-2009?

\section{Appendix A: Parameter estimates}

The following Table 2 presents the estimated parameters for the model used in this paper.

18 See Masson (1999) for theoretical support to this argument. 
Table 2 Parameter estimates for $\operatorname{AR}(1)$-FIAPARCH$(1, d, 1)$ and $\operatorname{cDCC}(1,1)$ process

\begin{tabular}{|c|c|c|c|c|c|c|c|}
\hline & $\varphi$ & $\omega \times 10^{4}$ & $d$ & $\phi$ & $\beta$ & $\gamma$ & $\delta$ \\
\hline France & $\begin{array}{l}0.076 * * * \\
(0.000)\end{array}$ & $\begin{array}{l}1.353 \\
(0.647)\end{array}$ & $\begin{array}{l}0.343 * * * \\
(0.000)\end{array}$ & $\begin{array}{l}0.372 * * * \\
(0.000)\end{array}$ & $\begin{array}{l}0.664 * * * \\
(0.000)\end{array}$ & $\begin{array}{l}0.111 \\
(0.244)\end{array}$ & $\begin{array}{l}1.791 \text { *** } \\
(0.000)\end{array}$ \\
\hline Germany & $\begin{array}{l}0.128 * * * \\
(0.000)\end{array}$ & $\begin{array}{l}0.368 \\
(0.724)\end{array}$ & $\begin{array}{l}0.328 * * * \\
(0.001)\end{array}$ & $\begin{array}{l}0.360 * * * \\
(0.000)\end{array}$ & $\begin{array}{l}0.672 * * * \\
(0.001)\end{array}$ & $\begin{array}{l}0.101 \\
(0.377)\end{array}$ & $\begin{array}{l}2.016 * * * \\
(0.000)\end{array}$ \\
\hline Italy & $\begin{array}{l}0.079 * * * \\
(0.000)\end{array}$ & $\begin{array}{l}0.883 \\
(0.406)\end{array}$ & $\begin{array}{l}0.249 * * \\
(0.049)\end{array}$ & $\begin{array}{l}0.131 \\
(0.875)\end{array}$ & $\begin{array}{l}0.289 \\
(0.760)\end{array}$ & $\begin{array}{l}-0.287 * \\
(0.087)\end{array}$ & $\begin{array}{l}1.992 * * * \\
(0.000)\end{array}$ \\
\hline Belgium & $\begin{array}{l}0.137 * * * \\
(0.000)\end{array}$ & $\begin{array}{l}6.441 \\
(0.463)\end{array}$ & $\begin{array}{l}0.335 * * * \\
(0.000)\end{array}$ & $\begin{array}{l}0.365^{* * * *} \\
(0.004)\end{array}$ & $\begin{array}{l}0.586 * * * \\
(0.000)\end{array}$ & $\begin{array}{l}-0.051 \\
(0.626)\end{array}$ & $\begin{array}{l}1.512 * * * \\
(0.000)\end{array}$ \\
\hline Netherlands & $\begin{array}{l}0.102 * * * \\
(0.000)\end{array}$ & $\begin{array}{l}5.714 \\
(0.729)\end{array}$ & $\begin{array}{l}0.373 * * * \\
(0.000)\end{array}$ & $\begin{array}{l}0.371 * * * \\
(0.000)\end{array}$ & $\begin{array}{l}0.703 \text { *** } \\
(0.000)\end{array}$ & $\begin{array}{l}0.146 \\
(0.280)\end{array}$ & $\begin{array}{l}1.435 * * \\
(0.037)\end{array}$ \\
\hline Ireland & $\begin{array}{l}0.084 * * * \\
(0.000)\end{array}$ & $\begin{array}{l}2.119 \\
(0.359)\end{array}$ & $\begin{array}{l}0.486 * * * \\
(0.000)\end{array}$ & $\begin{array}{l}0.437 * * * \\
(0.000)\end{array}$ & $\begin{array}{l}0.771 * * * \\
(0.000)\end{array}$ & $\begin{array}{l}-0.135 \\
(0.259)\end{array}$ & $\begin{array}{l}1.653 \text { *** } \\
(0.000)\end{array}$ \\
\hline Spain & $\begin{array}{l}0.091 * * * \\
(0.000)\end{array}$ & $\begin{array}{l}0.796 \\
(0.416)\end{array}$ & $\begin{array}{l}0.346 * * * \\
(0.000)\end{array}$ & $\begin{array}{l}0.358 * * * \\
(0.000)\end{array}$ & $\begin{array}{l}0.625 * * * \\
(0.000)\end{array}$ & $\begin{array}{l}-0.298 * * \\
(0.019)\end{array}$ & $\begin{array}{l}1.840 * * * \\
(0.000)\end{array}$ \\
\hline Portugal & $\begin{array}{l}0.168 * * * \\
(0.000)\end{array}$ & $\begin{array}{l}0.158 \\
(0.676)\end{array}$ & $\begin{array}{l}0.467 * * * \\
(0.000)\end{array}$ & $\begin{array}{l}0.383 * * * \\
(0.000)\end{array}$ & $\begin{array}{l}0.729 * * * \\
(0.000)\end{array}$ & $\begin{array}{l}-0.280 * * * \\
(0.003)\end{array}$ & $\begin{array}{l}1.838 * * * \\
(0.000)\end{array}$ \\
\hline Austria & $\begin{array}{l}0.111 * * * \\
(0.000)\end{array}$ & $\begin{array}{l}1.263 \\
(0.679)\end{array}$ & $\begin{array}{l}0.363 * * * \\
(0.004)\end{array}$ & $\begin{array}{l}0.381 * * * \\
(0.000)\end{array}$ & $\begin{array}{l}0.705^{* * *} \\
(0.000)\end{array}$ & $\begin{array}{l}0.080 \\
(0.341)\end{array}$ & $\begin{array}{l}1.772 * * * \\
(0.002)\end{array}$ \\
\hline Finland & $\begin{array}{l}0.112 * * * \\
(0.000)\end{array}$ & $\begin{array}{l}2.661 \\
(0.596)\end{array}$ & $\begin{array}{l}0.425^{* * *} \\
(0.001)\end{array}$ & $\begin{array}{l}0.354 * * * \\
(0.000)\end{array}$ & $\begin{array}{l}0.749 * * * \\
(0.000)\end{array}$ & $\begin{array}{l}0.156 \\
(0.136)\end{array}$ & $\begin{array}{l}1.551 * * * \\
(0.001)\end{array}$ \\
\hline Greece & $\begin{array}{l}0.206 * * * \\
(0.000)\end{array}$ & $\begin{array}{l}0.643 \\
(0.284)\end{array}$ & $\begin{array}{l}0.585^{* * *} \\
(0.000)\end{array}$ & $\begin{array}{l}0.202 * \\
(0.098)\end{array}$ & $\begin{array}{l}0.619 * * * \\
(0.000)\end{array}$ & $\begin{array}{l}-0.148^{*} \\
(0.062)\end{array}$ & $\begin{array}{l}1.802 * * * \\
(0.000)\end{array}$ \\
\hline \multicolumn{8}{|c|}{ cDCC parameters } \\
\hline $\bar{a}$ & & & & & & & $b$ \\
\hline $\begin{array}{l}0.027 * * * \\
(0.000)\end{array}$ & & & & & & & $\begin{array}{l}0.964 * * * \\
(0.000)\end{array}$ \\
\hline
\end{tabular}

The values in the parentheses are $p$ values obtained from robust standard errors $*$, ** and ***Denote significance at 10,5 and $1 \%$ levels respectively

\section{References}

Abad, P., Chulia, H., \& Gomez-Puig, M. (2010). European government bond market integration. Journal of Banking \& Finance, 34, 2851-2860.

Aielli, G. P. (2013). Dynamic conditional correlation: On properties and estimation. Journal of Business \& Economic Statistics, 31, 282-299.

Barrios, S., Iversen, P., Lewandowska, M., Setzer, R. (2009). Determinants of intra-euro area government bond spreads during the financial crisis. European Commission Economic Papers 388.

Barro, D., \& Basso, A. (2010). Credit contagion in a network of firms with spatial interaction. European Journal of Operational Research, 205, 459-468.

Beber, A., Brandt, M. W., \& Kavajecz, K. A. (2009). Flight-to-quality or flight-to-liquidity? Evidence from the Euro-area bond market. Review of Financial Studies, 22, 925-957.

Beirne, J., \& Fratscher, M. (2013). The pricing of sovereign risk and contagion during the European sovereign debt crisis. Journal of International Money and Finance, 34, 60-82.

Bernoth, K., von Hagen, J., \& Schuknecht, L. (2012). Sovereign risk premiums in the European government bond market. Journal of International Money and Finance, 31, 975-995. 
Caccioli, F., Farmer, J. D., Foti, N., \& Rockmore, D. (2015). Overlapping portfolios, contagion, and financial stability. Journal of Economic Dynamics and Control, 51, 50-63.

Capponin, A., \& Chen, P. C. (2015). Systemic risk mitigation in financial networks. Journal of Economic Dynamics and Control, 58, 152-166.

Christiansen, C. (2014). Integration of European bond markets. Journal of Banking \& Finance, 42, 191-198.

Codogno, L., Favero, C., \& Missale, A. (2003). Yield spreads on EMU government bonds. Economic Policy, 37, 527-529.

Conrad, C., Karanasos, M., \& Zeng, N. (2008). Multivariate fractionally integrated APARCH modeling of stock market volatility: A multi-country study. Discussion Paper Series, University of Heidelberg.

Dewachter, H., Iania, L., Lyrio, M., \& de Sola Perea, M. (2015). A macro-financial analysis of the euro area sovereign bond market. Journal of Banking \& Finance, 50, 308-325.

Ehrmann, M., Fratzcher, M., Gurkaynak, R., \& Swanson, E. T. (2011). Convergence and anchoring of yield curves in the Euro area. Review of Economics and Statistics, 93, 350-364.

Engle, R. F. (2002). Dynamic conditional correlation: A simple class of multivariate generalized autoregressive conditional heteroskedasticity models. Journal of Business \& Economic Statistics, 20, 339-350.

Fatas, A. (2010). The economics of achieving fiscal sustainability. Paper presented at the Academic Consultants Meeting - Board of Governors, Federal Reserve

Gruner, H. P. (2010). Why EMU is not a failure? European Journal of Political Economy, 26, 1-11.

Iara, A., \& Wolff, G. B. (2014). Rules and risk in the Euro area. European Journal of Political Economy, 34, 222-236.

Iori, G., De Masi, G., Precup, O., Gabbi, G., \& Caldarelli, G. (2008). A network analysis of the Italian overnight money market. Journal of Economic Dynamics and Control, 32, 259-278.

Lavielle, M. (2005). Using penalized contrasts for the change-point problem. Signal Processing, 85, 15011510 .

Markellos, R. N., Psychoyios, D., \& Schneider, F. (2016). Sovereign debt markets in light of the shadow economy. European Journal of Operational Research, 252, 220-231.

Masson, P. (1999). Contagion: Macroeconomic models with multiple equilibria. Journal of International Money and Finance, 18, 587-602.

Minoiu, C., \& Reyes, J. A. (2013). A network analysis of global banking: 1978-2010. Journal of Financial Stability, 9, 168-184.

Nagurney, A., \& Ke, K. (2006). Financial networks with intermediation: Risk management with variable weights. European Journal of Operational Research, 172, 40-63.

Paltalidis, N., Gounopoulos, D., Kizys, R., \& Koutelidakis, Y. (2015). Transmission channels of systemic risk and contagion in the European financial network. Journal of Banking \& Finance, 61, 36-52.

Pozzi, L., \& Wolswijk, G. (2012). The time-varying integration of euro area government bond markets. European Economic Review, 56, 36-53.

Pragidis, I. C., Aielli, G. P., Chionis, D., \& Schizas, P. (2015). Contagion effects during financial crisis: Evidence from the Greek sovereign bonds market. Journal of Financial Stability, 18, 127-138.

Reboredo, J. C., \& Ugolini, A. (2015). Systemic risk in european sovereign debt markets: A CoVaR-copula approach. Journal of International Money and Finance, 51, 214-244.

Schuknecht, L., von Hagen, J., \& Wolswijk, G. (2009). Government risk premiums in the bond market: EMU and Canada. European Journal of Political Economy, 25, 371-384.

Sibbertsen, P., Wegener, C., \& Basse, T. (2014). Testing for a break in the persistence in yield spreads of EMU government bonds. Journal of Banking \& Finance, 41, 109-118.

Tola, V., Lillo, F., Gallegati, M., \& Mantegna, R. N. (2008). Cluster analysis for portfolio optimization. Journal of Economic Dynamics and Control, 32, 235-258.

Tse, Y. K. (1998). The conditional heteroskedasticity of the yen-dollar exchange rate. Journal of Applied Econometrics, 13, 49-55.

Tumminello, M., Lillo, F., \& Mantegna, R. N. (2010). Correlation, hierarchies, and networks in financial markets. Journal of Economic Behavior \& Organization, 75, 40-58.

von Hagen, J., Schuknecht, L., \& Wolswijk, G. (2011). Government bond risk premiums in the EU revisited: The impact of the finanial crisis. European Journal of Political Economy, 27, 36-43. 